Anuario de la Facultad de Derecho. Universidad de Extremadura 36 (2020): 249-274 ISSN: 0213-988X - ISSN-e: 2695-7728

Doi: https://doi.org/10.17398/2695-7728.36.249

\title{
LÍMITES DE LA VALIDEZ DE LA PRUEBA DE DETECTIVES: PRIVACIDAD Y PROTECCIÓN DE DATOS
}

\author{
LIMITS OF THE VALIDITY OF THE DETECTIVE'S TEST: \\ PRIVACY AND DATA PROTECTION
}

\author{
ANTONio Folgoso OLMo \\ Colegio de Abogados de Granada
}

Recibido: 16/10/2020 Aceptado: 18/12/2020

\section{RESUMEN}

En el presente trabajo se analiza la prueba de detectives y cómo esta se ha visto afectada por la entrada en vigor del Reglamento General de Protección de Datos. En primer lugar, se estudian los requisitos que se derivan de la normativa en materia de seguridad privada. A continuación, se examinan el derecho a la protección de datos y las novedades en cuanto a su regulación. Por último, se abordan las particularidades existentes en el ámbito de la jurisdicción social, especialmente en aquellos supuestos en los que se declara que el detective no ha respetado los derechos fundamentales del investigado.

Palabras clave: Datos personales, privacidad, detective, prueba.

\section{ABSTRACT}

The present paper analyses the detective evidence and how it has been affected by the implementation of the General Data Protection Regulation (GDPR). Firstly, the requirements arising from the law on private security are analysed for this purpose. Secondly, 
the right to data protection and the news regarding its regulation are discussed. Lastly, the existing particularities in the field of social jurisdiction are addressed, especially in those cases in which it is declared that the detective has not respected the fundamental rights of the investigated.

Keywords: Personal data, privacy, detective, evidence.

Sumario: 1. Introducción. 2. Las obligaciones derivadas de la investigación. 2.1. El encargo. 2.2. La investigación. 2.3. Terminación del trabajo. 3. El derecho a la protección de datos: regulación vigente y afectación a las investigaciones privadas. 3.1. Derecho a la protección de datos y aproximación a su regulación vigente. 3.2. Obligaciones informativas respecto del investigado. 3.3. La obtención y tratamiento de los datos frente a los derechos del afectado. 4. El informe de detectives como medio de prueba. 4.1. La prueba de detectives en la jurisdicción social. 4.2. El control judicial de la validez de la prueba. 4.3. Implicaciones de la prueba obtenida con vulneración de derechos. 5. Conclusiones.

\section{INTRODUCCIÓN}

La prueba de detectives tiene una especial relevancia en la jurisdicción social. Su utilización se ha extendido en muy distintos tipos de procedimientos, tanto de carácter laboral como en materia prestacional.

Con respecto al ámbito laboral, su virtualidad se extiende generalmente a los procedimientos derivados del ejercicio por parte del empleador de su potestad disciplinaria: despidos e imposición de sanciones ${ }^{1}$. En estos supuestos, es frecuente que el empresario que trata de demostrar la comisión por parte de un trabajador de un incumplimiento sancionable decida acudir a este tipo de prueba, con el objeto de acreditar la existencia de infracciones de cara al posterior

$1 \mathrm{Al}$ respecto, se ha señalado la necesidad de distinguir la facultad patronal de control del trabajo respecto de la disciplinaria, considerando que son autónomas; sin embargo, la potestad de control con frecuencia se ha calificado como instrumental del resto de poderes empresariales. En este sentido, véase Jesús Cruz Villalón, "Las facultades de control del empleador ante los cambios organizativos y tecnológicos", Temas laborales: Revista andaluza de trabajo y bienestar social, núm. 150 (2019): 1344. En todo caso, nada impide que, como el resto de las facultades del empresario, pueda ser ejercitada de forma torticera o con un propósito lesivo de derechos. Un ejemplo de ello es la prohibición de someter a "vigilancia singular" a los representantes de los trabajadores, como ha establecido reiterada Jurisprudencia, entre la que puede referirse la STS de 2 de noviembre de 1989 (ECLI:ES:TS:1989:5988). 
procedimiento judicial. Las investigaciones realizadas por los detectives suelen ser especialmente útiles en los casos en que se sospecha que el trabajador realiza actuaciones transgresoras de la buena fe o desleales, ya sea fuera del centro de trabajo (ejercicio de competencia desleal, simulación de bajas médicas, empleo indebido del crédito horario, etc.), ya sea dentro del mismo (otras actuaciones del trabajador contrarias a los intereses empresariales, tales como hurtos).

Esta prueba no limita su potencialidad a los supuestos de carácter laboral, sino que es también empleada en materia de Seguridad Social, especialmente por las mutuas patronales. Las entidades colaboradoras acuden con frecuencia a detectives para realizar seguimientos a trabajadores por cuenta propia y ajena, que se encuentran en situación de baja médica, al objeto de acreditar, incluso frente a lo reflejado en sus pruebas médicas, que han recuperado la capacidad laboral. También se utiliza habitualmente como prueba frente a las demandas de reconocimiento de prestaciones, tratando de demostrar que las dolencias alegadas no justifican el grado de incapacidad reclamado.

Todo lo expuesto hace de la prueba de detectives una herramienta especialmente valiosa y ampliamente extendida. Sin embargo, al igual que el resto de los medios de prueba, debe ser respetuosa con los derechos -fundamentales y ordinarios- de los investigados, ya que lo contrario podrá implicar su anulación, perdiendo así su utilidad.

En este trabajo se realiza un análisis en torno a uno de estos límites, constituido por el derecho a la protección de datos, especialmente a la vista de la aprobación del Reglamento (UE) 2016/679 del Parlamento Europeo y del Consejo, aprobado el 27 de abril de 2016, relativo a la protección de las personas físicas en lo que respecta al tratamiento de datos personales y a la libre circulación de estos datos (en adelante, RGPD).

\section{LAS OBLIGACIONES DERIVADAS DE LA INVESTIGACIÓN}

La actuación de los detectives se regula en el art. 48.1 de la Ley 5/2014, de 4 de abril, de Seguridad Privada (en adelante, LSP). Este precepto establece que 
sus servicios consistirán en la realización de averiguaciones que resulten necesarias para la obtención y aportación, por cuenta de terceros legitimados, de información y pruebas sobre conductas o hechos privados.

Tal obtención de pruebas podrá realizarse de muy diversas maneras. Junto a la posibilidad de que el detective presencie de manera directa los hechos (lo que, sin duda, tendrá relevancia de cara a los eventuales procesos judiciales que puedan desencadenarse a raíz del resultado de la investigación), los importantes avances tecnológicos permiten la captación de imagen y sonido en distintos soportes. De esta manera, podrá reforzarse con datos objetivos la mera versión del detective, lo que sin duda aumentará las posibilidades de la parte que propone la prueba a la hora de formar la convicción del juzgador. En este sentido, no es infrecuente que los propios servicios ofrecidos por estos profesionales incluyan la utilización de microcámaras y otros mecanismos de grabación.

Obviamente, todo lo anterior puede implicar la existencia de colisiones con los derechos de los investigados. Por este motivo, la normativa vigente arbitra una serie de procedimientos que deberán seguirse, con el objeto de garantizar que tales derechos sean respetados. Estos requisitos no deben interpretarse como meros mecanismos formales, sino que, por su conexión última con los derechos fundamentales del afectado, habrán de ser analizados de manera exhaustiva y realizando una cuidadosa ponderación de los valores en juego.

\subsection{EL ENCARGO}

Con carácter previo al inicio de la investigación, resulta imprescindible que se produzca un encargo al detective (art. 48 LSP). Aunque pudiera parecer una cuestión obvia, la realidad es que tanto en la necesidad de que el encargo sea previo, como en los detalles de su formalización, se encuentra una parte fundamental de la validez del mismo. Por lo tanto, para ser adecuado a Derecho deberá cumplir el citado encargo un triple requisito: ser previo al inicio de la investigación, apoyarse en un interés legítimo y que este último se acredite. Se analizan a continuación. 
La primera exigencia consiste en que el encargo sea previo al inicio de la investigación, de forma que el detective solo pueda actuar previa solicitud del cliente y no con independencia del mismo. Queda prohibido, de esta manera, que los detectives puedan recopilar información de manera autónoma para ofrecerla a posteriori a sus potenciales clientes. Para ello, deberá realizarse un expediente de contratación en el que será imprescindible que conste la fecha de la realización del encargo. Además, deberá comunicarse su celebración a la autoridad pertinente, con carácter previo al inicio de los servicios (art. 9.2 LSP), si bien en el mismo bastará que consten los datos de identificación de las partes, sin más detalle.

El segundo requisito implica que el cliente deberá invocar un interés legítimo al detective, que justifique la necesidad de la investigación. Ante este, el detective deberá valorar la suficiencia del mismo, debiendo desatender peticiones caprichosas, arbitrarias, lesivas de derechos fundamentales, etc. En este sentido, se ha venido considerando que la existencia del contrato de trabajo, y de la potestad de control implícita al mismo, puede ser fundamento de ese interés legítimo ${ }^{2}$.

Finalmente, se exige que el cliente acredite dicho interés. Resulta fundamental diferenciar este requisito del anterior, en tanto que no bastará con hacer referencia al citado interés, sino que deberá acreditarlo quien realiza el encargo, poniendo en manos del detective las pruebas pertinentes.

Uno de los problemas fundamentales de la regulación vigente, y que ya se anticipa, radica en la ausencia de garantías para los derechos de los investigados. Debe tenerse en cuenta que, en muchos casos, la existencia de la investigación no es siquiera conocida por aquellos a quienes afecta. Además, la regulación del contenido del expediente de contratación no establece la obligación de ser

2 Cuestión bien distinta será la valoración concreta de si ese interés se encontraba justificado, etc. No puede caerse en el automatismo de considerar que, por el hecho de encontrarse un trabajador en el ámbito de organización de un empresario, este último se encuentra en todo caso legitimado para establecer un sistema de vigilancia sobre el primero que afecte, por ejemplo, a las actividades realizadas fuera de la jornada de trabajo. En este sentido, véase Eva Garrido Pérez, "La actuación de los detectives privados como instrumento del control empresarial”, Temas laborales: Revista andaluza de trabajo y bienestar social, núm. 150 (2019): 236. 
sometida a ningún tipo de registro público (más allá del descrito en los apartados 2 y 3 del art. 9 LSP). La consecuencia de lo anterior es que resulta muy difícil para el investigado acreditar que el encargo se ha realizado cumpliendo con los requisitos señalados.

De este modo, comenzando por el momento mismo de la contratación, se ha destacado que en la práctica nada impide que la mera desconfianza pueda traducirse en la contratación de los servicios de un detective, o incluso que dicha contratación tenga lugar antes de agotar otras vías menos invasivas (siendo cuestión distinta que esta prueba sea finalmente aceptada en sede judicial)3. Igualmente, no es descartable que el detective pueda aceptar la investigación sin que se le haya alegado y acreditado previamente dicho interés legítimo; y solo tras la finalización de la investigación, en caso de encontrarse, incluir la justificación de su necesidad en el citado expediente de contratación, corrigiéndolo. Por el contrario, si finalmente no se confirmasen las sospechas del cliente y la investigación no encuentra la información o pruebas que se buscaban, bastará a ambos -detective y cliente- con dar por resuelto el encargo sin que el investigado tenga conocimiento en ningún momento de lo ocurrido, pese a haber quedado comprometido su derecho a la privacidad.

\subsection{LA INVESTIGACIÓN}

Una vez efectuado el encargo, el art. 48.3 LSP regula algunas exigencias que debe cumplir la investigación. A tal efecto, se establecen determinados límites que no podrá horadar el detective4.

La primera restricción consiste en que la investigación debe moverse dentro de los contornos trazados por el cliente, no debiendo trascender del encargo

3 Juan Miguel Díaz Rodríguez, Detectives y vigilantes privados en el ámbito laboral: poder empresarial y prueba judicial (Valencia: Tirant lo Blanch, 2013), versión electrónica, base de datos Tirant online, capítulo III ("Poder empresarial de control mediante vigilantes y detectives"), apartado 2.1 ("La utilización por las empresas de las posibilidades que ofrece la LSP”).

4 Tales límites se encuentran conectados con los derechos fundamentales del afectado. Aunque, como se verá a continuación, algunos de ellos no se vinculan de forma inmediata a tales derechos, su regulación trata de evitar que pueda desencadenarse una vulneración para los mismos. 
realizado5. No está permitido, por tanto, que el detective vaya más allá y decida acceder a otros aspectos distintos de la vida de la persona investigada.

La segunda frontera que no debe ser traspasada hace referencia a los ámbitos que no podrán ser investigados, consistentes en los aspectos de la vida íntima de las personas que transcurra en sus domicilios u otros lugares reservados. De este modo, se establece una limitación conectada con los derechos fundamentales a la inviolabilidad del domicilio, a la intimidad, así como a la vida privada. Particularmente respecto de los dos últimos, puede apreciarse que la norma los diferencia como dos derechos distintos, pudiendo afirmarse que "el ámbito de la privacidad es considerablemente más amplio que el correspondiente a la intimidad"6. En este sentido, DÍAZ RODRÍGuEZ destaca la necesidad de distinguir entre lo público y lo no público, especificando que no todo lo no público debe quedar comprendido dentro del concepto de intimidad (a cuyo efecto, acude a la distinción entre lo público, lo privado y lo íntimo). Además, que la ley vigente permita investigar la vida privada de una persona no puede equipararse con que dicha actuación sea lícita en todo caso7.

El tercer límite se vincula con los medios empleados para la realización de las investigaciones. Se proscribe la utilización de medios personales, materiales o técnicos que atenten contra los derechos fundamentales al honor, intimidad personal o familiar, a la propia imagen, al secreto de las comunicaciones o -ya se alude en este punto- a la protección de datos. También se prohíbe el empleo de medios, vehículos o distintivos que puedan inducir a confusión con los de las Fuerzas y Cuerpos de Seguridad (art. 48.4 LSP).

Finalmente, se establece una última barrera que, sin embargo, no se encuentra regulada en términos tan absolutos como las anteriores. Este último

5 Díaz Rodríguez: Detectives y vigilantes privados... (Bibl. Cit.), capítulo III ("Poder empresarial de control mediante vigilantes y detectives"), apartado 2.6 (“Otras posibles limitaciones").

6 Cruz Villalón, "Las facultades de control del empleador ...”, 38. Al respecto, se ha dicho que "el concepto de vida privada es muy amplio, genérico y engloba a todo aquello que no es, o que no queremos que sea de general conocimiento. Dentro de ello, existe un núcleo que protegemos con más celo, con mayor fuerza, porque lo entendemos como esencial en la configuración de nuestra persona. A esto último lo denominamos intimidad”: María Mercedes Serrano Pérez y Lucrecio Rebollo Delgado, El derecho fundamental a la intimidad, $2^{\text {a }}$ edición (Madrid: Editorial Dykinson, 2005), 74.

7 Díaz Rodríguez: Detectives y vigilantes privados... (Bibl. Cit.) 
límite se constituye sobre la jurisprudencia existente hasta la fecha, relativa a la necesidad de que los servicios de investigación privada se ejecuten de forma que respeten los principios de razonabilidad, necesidad, idoneidad y proporcionali$\mathrm{dad}^{8}$. Como puede suponerse, esto implica un ejercicio valorativo por parte del detective, que deberá ponderar los valores en juego bajo su propia responsabilidad. A su contenido se regresará más adelante.

\subsection{TERMINACIÓN DEL TRABAJO}

Las obligaciones para el detective respecto de la investigación no concluyen con la finalización de su trabajo. A partir de ahí, surgen determinadas exigencias autónomas que debe atender, conectadas con la integridad del trabajo realizado y con la discreción que debe caracterizarlo.

La primera, regulada en el art. 49 LSP, es la elaboración del informe de investigación, en el que se deberá hacer referencia, entre otros aspectos, a los datos de quien realizó el encargo, el objeto de la contratación, los medios, los resultados, los detectives intervinientes y las actuaciones realizadas. En dicho informe no podrán incluirse otros aspectos que hayan podido averiguarse, distintos del objeto de la investigación. Entre estos, el art. 49.2 LSP establece la prohibición expresa de conservar datos de carácter personal especialmente protegidos. Este informe se entregará al cliente al finalizar la investigación, quedando igualmente a disposición de la autoridad policial para los supuestos de inspección de la actividad del detective (art. 49.2 en relación con el art. 54.5 LSP).

La segunda obligación se vincula con el deber de sigilo de los detectives. Este se traduce en que las investigaciones y datos obtenidos solo podrán ponerse a disposición del cliente o, en su caso, de la autoridad policial o judicial (art. 49.5 LSP); pero también en la prohibición de facilitar datos a terceros (art. 50 LSP). Se trata de cuestiones que el legislador ha considerado claves, habiendo establecido que su incumplimiento se encuentra tipificado como una infracción muy 
grave (art. 58.1.c LSP), sancionable con importantes multas (art. 61.1.a LSP) e, incluso, con la extinción de la autorización (art. 61.1.b LSP); todo ello sin perjuicio incluso de las posibles responsabilidades penales que puedan desprenderse, teniendo en cuenta que la revelación de tales datos podrá constituir incluso un delito de revelación de secretos (art. 197 y siguientes del Código Penal).

\section{EL DERECHO A LA PROTECCIÓN DE DATOS: REGULACIÓN VIGENTE Y AFECTACIÓN A LAS INVESTIGACIONES PRIVADAS}

Dentro del conjunto de los derechos fundamentales, uno de los que mayor revolución ha experimentado en los últimos años es el derecho a la protección de datos. A continuación, se realiza una aproximación sintética a su naturaleza, se analiza su regulación actual y se desarrollan las consecuencias que supone para las actuaciones de los detectives.

\subsection{DERECHO A LA PROTECCIÓN DE DATOS Y APROXIMACIÓN A SU REGULACIÓN} VIGENTE

Es cuestión conocida que el derecho a la protección de datos no se encuentra explícitamente regulado en nuestro texto constitucional. Se trata de un derecho laboral inespecífico 9 , que ha ido desarrollándose a partir de la conjunción entre el derecho a la intimidad (art. 18.1 CE) y la previsión constitucional de la necesidad de limitar el uso de la informática de forma que se garanticen los derechos de los ciudadanos (art. 18.4 CE). Partiendo de esas consideraciones, se ha sostenido un amplio debate respecto de si se trata de un derecho fundamental autónomo respecto del derecho a la intimidad o si es instrumental al mismo ${ }^{10}$.

9 Expresión acuñada por primera vez por Manuel Carlos Palomeque López, Los derechos laborales en la Constitución Española (Madrid: Centro de Estudios Constitucionales, 1991): 31.

10 Sin embargo, la doctrina también ha remarcado que, aunque la jurisprudencia constitucional haya tratado de destacar la autonomía del derecho del 18.4, esta no puede ser absoluta en tanto que la protección de datos comprende el derecho fundamental a la intimidad, aunque vaya más allá. En este particular, véase Antonio Vicente Sempere Navarro y Carolina San Martín Mazzuconi, Nuevas tecnologías y relaciones laborales (Valencia: Tirant lo Blanch, 2002): 120-122. 
$\mathrm{Al}$ respecto, la STC 254/1993, de 20 de julio, ya señaló que el art. $18.4 \mathrm{CE}$ constituía un mecanismo de garantía de otros derechos (principalmente, el honor y la intimidad), aunque también es, en sí mismo, un derecho fundamental "a la libertad frente a las potenciales agresiones a la dignidad y a la libertad de la persona provenientes de un uso ilegítimo del tratamiento mecanizado de datos”. La posterior STC 292/2000, de 30 de noviembre, añadió que su contenido "excede el ámbito propio del derecho fundamental a la intimidad (art. 18.1 CE), y que se traduce en un derecho de control sobre los datos relativos a la propia persona”. De esta manera, se hace referencia al derecho de cualquier ciudadano a controlar el uso de sus datos personales y a oponerse a que estos sean utilizados para fines distintos de los que justificaron su obtención. Además, "este derecho entraña una facultad de disponer sobre la revelación y el uso de los datos personales, en todas las fases de elaboración y utilización de estos datos, es decir, su acumulación, su transmisión, su modificación y cancelación”"11.

A la vista de lo anterior, puede sostenerse que se ha reconocido un derecho fundamental que expresamente no se encontraba regulado en la CE: un "derecho a la autodeterminación informativa”. Este concepto fue acuñado por primera vez por el Tribunal Constitucional Federal alemán en 1983, describiéndolo como "la facultad del individuo de decidir cuándo y con qué limites dar a conocer situaciones de su vida privada, siendo necesaria la protección del individuo ante la recopilación, almacenamiento, uso y cesión ilimitados de sus datos" ${ }^{12}$.

El derecho a la protección de datos ha sido positivizado en importantes textos normativos de ámbito superior al nacional, como son el art. 16 del Tratado de Funcionamiento de la Unión Europea y el art. 8 de la Carta de Derechos Fundamentales de la Unión Europea. Lo anterior implica que su interpretación deberá realizarse también a la luz del desarrollo que ha tenido de dicho derecho en tales espacios jurídicos.

11 José Ignacio García Ninet y Fernando de Vicente Pachés, "El derecho valor a la dignidad humana y el derecho a la protección de datos personales en la Constitución Europea”, Revista del Ministerio de Trabajo y Asuntos Sociales, núm. 57 (2005): 161.

12 Andoni Polo Roca, "El derecho a la protección de datos personales y su reflejo en el consentimiento del interesado”. Revista de Derecho Político, núm. 108 (2020): 172. 
Dentro de la regulación actual en materia de protección de datos, ocupa un papel determinante el RGPD. Este texto normativo deroga la Directiva 95/46/CE, que sentaba hasta la fecha las bases en la materia. Además, debe tenerse en cuenta que el citado RGPD permite a los Estados miembros establecer una regulación específica y desarrollar la cuestión a través de sus distintas fuentes normativas ${ }^{13}$ (en nuestro caso, eso se traduce en una habilitación para ello tanto a la Ley como a la negociación colectiva).

Como suele ser propio de los textos de esta clase, el RGPD comienza estableciendo una serie de definiciones. Entre otras, es de especial interés el concepto de 'datos personales', que se definen como "toda información sobre una persona física identificada o identificable” (art. 4.1 RGPD), estableciéndose al respecto un criterio amplio (u "omnicomprensivo"14). Por tanto, la información obtenida por un detective privado debe incluirse dentro del concepto de datos personales ${ }^{15}$. En consecuencia, la regulación del RGPD afecta, decididamente, a las investigaciones privadas ${ }^{16}$, estableciendo nuevos límites que deben ser considerados.

También es de gran relevancia el concepto de 'tratamiento' incluido en el RGPD, dentro del que se incluye cualquier operación realizada sobre datos personales, a cuyo efecto también se ha atendido a una noción especialmente amplia (art. 4.2)17. Partiendo de lo anterior, se establece que el tratamiento solo será lícito si cumple una serie de condiciones, entre las que se encuentra que el

13 Considerando 155 del RGPD

14 Jesús Ramón Mercader Uguina, "La protección de datos del informe de detectives privados". En La actividad de los detectives privados en el ámbito laboral. Aspectos sustantivos y procesales de la obtención de la prueba, dirigido por Eduardo Enrique Taléns Visconti y $\mathrm{M}^{\mathrm{a}}$ Ángeles Valls Genovard (Madrid: Wolters Kluwer, 2020), 292

15 Esta era la interpretación que ya había realizado el propio TJUE en su sentencia de 7 de noviembre de 2013, c-473/12 (ECLI:EU:C:2013:715).

16 Las públicas quedan excluidas de su ámbito de aplicación, al amparo del art. 2.1.d, en materia de prevención, investigación, detección y enjuiciamiento de infracciones penales. Por lo tanto, el RGPD es de aplicación a la investigación pública de infracciones administrativas.

17 En concreto, se define de la siguiente manera: "cualquier operación o conjunto de operaciones realizadas sobre datos personales o conjuntos de datos personales, ya sea por procedimientos automatizados o no, como la recogida, registro, organización, estructuración, conservación, adaptación o modificación, extracción, consulta, utilización, comunicación por transmisión, difusión o cualquier otra forma de habilitación de acceso, cotejo o interconexión, limitación, supresión o destrucción”. 
interesado haya dado su consentimiento para el tratamiento (art. 6.1.a), que este sea necesario para la ejecución de un contrato en el que el interesado es parte (art. 6.1.b) o que el citado tratamiento sea necesario para la satisfacción de intereses legítimos ${ }^{18}$, siempre que sobre estos no prevalezcan los derechos fundamentales del interesado que requieran la protección de datos personales (art. 6.1.f) ${ }^{19}$. Así pues, el tratamiento de datos solo será ajustado a Derecho cuando exista habilitación legal para recabarlos y, además, resulte necesario para el cumplimiento del contrato ${ }^{20}$. Estas normas pueden ser objeto de precisión en el ámbito nacional (art. 6.2), que deben respetar en todo caso los principios básicos respecto del tratamiento, entre los que hay que destacar el de limitación de finalidad y el de minimización. El primero establece que solo podrán ser recogidos "con fines determinados, explícitos y legítimos, y no serán tratados ulteriormente de manera incompatible con dichos fines” (art. 5.1.b). Por su parte, el principio de minimización establece que tales datos deberán ser "adecuados, pertinentes y limitados a lo necesario en relación con los fines para los que son tratados" (art. 5.1.c).

A lo anterior hay que añadir que el art. 9.1 RGPD establece la prohibición taxativa de realizar el tratamiento de determinados datos personales, entre los que se incluyen los datos relativos a la salud. A continuación, el art. 9.2 RGPD incluye una serie de excepciones tasadas, entre las que se encuentra que dicho

$18 \mathrm{Al}$ respecto, resulta de interés la STEDH de 27 de mayo de 2014, Asunto Flor Cabrera contra España, que considera que puede responder a una finalidad legítima la captación de imágenes de otra persona, cuando tiene como objeto ser aportada como prueba en juicio, al conectarse con el derecho a la tutela judicial efectiva.

19 La ponderación que este precepto obliga a realizar deberá ser especialmente escrupulosa por parte del responsable del tratamiento de los datos, habida cuenta de los intereses en juego. Al respecto, el considerando 47 del RGPD establece que "la existencia de un interés legítimo requeriría una evaluación meticulosa, inclusive si un interesado puede prever de forma razonable, en el momento y en el contexto de la recogida de datos personales, que pueda producirse el tratamiento con tal fin”. Dicha evaluación se traduce en la necesidad de superar "los juicios de idoneidad, necesidad y proporcionalidad en sentido estricto, pero especialmente el de 'necesidad' por venir así requerido [por el art. 6.1.b RGPD] para dar licitud al tratamiento de datos personales aun sin consentimiento del interesado": Garrido Pérez, "La actuación de los detectives privados ...", 245.

20 María Areta Martínez, "Solicitud de un certificado de antecedentes penales a los trabajadores de nuevo ingreso y tratamiento de datos de carácter personal. SAN-SOC núm. 14/2020, de 10 de febrero", Revista de Jurisprudencia Laboral, núm. 3 (2020). 
tratamiento sea necesario para el cumplimiento de obligaciones laborales o de seguridad social, siempre que una norma lo autorice.

\subsection{OBLIGACIONES INFORMATIVAS RESPECTO DEL INVESTIGADO}

En el caso de las investigaciones privadas, en tanto que con frecuencia consistirán en la recopilación de datos personales (mediante fotografías, vídeos...), obviamente no podrá recabarse el consentimiento previo del afectado, lo que haría inviable la investigación ${ }^{21}$.

No obstante, el RGPD establece la obligación del responsable del tratamiento de facilitar determinada información al interesado, cuando los datos personales no se hayan facilitado por este. Entre otros aspectos, dicha información deberá consistir en los fines del tratamiento (art. 14.1.c), las categorías de datos personales de los que se trate (art. 14.1.d), los destinatarios de los mismos (art. 14.1.e), los intereses legítimos invocados por el tercero, que ha encargado la investigación (art. 14.2.b en relación al art. 6.1.f). La comunicación deberá efectuarse a la mayor brevedad y, en todo caso, antes de que transcurra un mes desde la obtención de los datos personales (art. 14.3.a), salvo que tales datos vayan a ser cedidos a un tercero, en cuyo caso deberá realizarse de manera inmediata a la cesión al tercero (art. 14.3.c).

Es cierto que el art. 14.5 RGPD prevé determinados supuestos donde dicha comunicación no debe realizarse, debiendo incluirse entre estos los casos en que ello pueda imposibilitar u obstaculizar gravemente el logro de los objetivos de tal tratamiento. Sin embargo, este precepto no consideramos que pueda ser de aplicación, en tanto que una vez que se realiza la investigación, no existe impedimento alguno para omitir su comunicación al interesado. Por el mismo motivo, el cumplimiento de estas obligaciones tampoco puede justificarse en la

21 En este sentido, se ha apuntado que "por propia esencia, la actividad de estos profesionales se debe realizar con ocultamiento al trabajador de que este control se está llevando a cabo. En la medida en que se acepta la licitud de utilizar este medio de control vía detectives privados es obvio que se está admitiendo que ello se lleve a cabo de manera oculta": Cruz Villalón, "Las facultades de control del empleador ...., 31 . 
aplicación del art. 23 RGPD, que establece determinadas limitaciones. No obstante, estas deberán ser necesarias y proporcionadas (art. 23.1 RGPD), no existiendo ningún motivo que justifique que el interesado no deba conocer el resultado de la investigación, una vez que esta ha finalizado.

El RGPD provocó la adaptación de la regulación vigente hasta el momento22 y la posterior aprobación de la Ley Orgánica 3/2018, de 5 de diciembre, de protección de datos personales y garantía de los derechos digitales (en adelante, LOPDyGDD) que, como no podía ser de otra manera, acogió los mandatos incorporados por el RGPD. En concreto, las previsiones contenidas en el art. 14 RGPD se referencian en el art. 11.3 LOPDyGDD, que establece la obligación del responsable del tratamiento de proporcionar la información señalada al afectado.

A nuestro juicio, la aplicación de la normativa señalada al caso de las investigaciones realizadas por detectives privados no deja lugar a dudas. No puede invocarse que en materia de investigaciones de detectives haya excepciones, en tanto que ni el RGPD ni la LOPDyGDD las establecen. Tampoco puede señalarse que las obligaciones previstas en la normativa vigente hagan inoperantes las investigaciones, en tanto que no se exige una comunicación previa, sino a posteriori. Es decir, según la normativa vigente, el cliente, una vez recogidos los datos tiene el plazo de un mes para comunicárselo al afectado. En ese momento, los datos ya están tomados (e, incluso, el informe realizado). Sin embargo, como se ha señalado, no hay motivo alguno que justifique que el investigado no pueda conocer que hay nuevos datos, distintos de los que inicialmente proporcionó, en poder de varios sujetos (detective, empresa o mutua que realiza el encargo, etc.).

3.3. LA OBTENCIÓN Y TRATAMIENTO DE LOS DATOS FRENTE A LOS DERECHOS DEL AFECTADO

En el ámbito de las relaciones laborales, la LOPDyGDD establece la obligación del empleador de informar previamente sobre el establecimiento de

22 Hacemos referencia a la Ley Orgánica 15/1999, de protección de datos de carácter personal. 
dispositivos de videovigilancia y grabación en el centro de trabajo (art. 89) y de sistemas de geolocalización (art. 90). Al respecto, se ha considerado que el empresario debe informar acerca de la posibilidad de sancionar para el supuesto de que se capten incumplimientos laborales por parte de los trabajadores; obligación informativa que tendrá que llevar a cabo en el momento de la instalación de los dispositivos o cada vez que un trabajador nuevo sea contratado ${ }^{23}$. Se trata de un precepto claro, para el que la norma no establece ningún tipo de excepción, ni tan siquiera cuando haya sospechas de actuaciones ilícitas en el centro de trabajo. De hecho, precisamente tales sospechas serán las que habilitarán la posibilidad de acudir a este tipo de medios tecnológicos, no siendo razonable instalarlos si no concurre justificación alguna para ello. De forma ilustrativa, el art. 89.3 LOPDyGDD establece que la utilización de tales dispositivos "se admitirá únicamente cuando resulten relevantes los riesgos para la seguridad de las instalaciones, bienes y personas derivados de la actividad que se desarrolle en el centro de trabajo". Por lo tanto, aunque en términos generales se ha señalado que nada prohíbe realizar grabaciones ocultas 24 , la nueva regulación instituye la prohibición de realizar grabaciones de este modo (esto es, sin información previa), cuando tienen lugar en el centro de trabajo; sin que el hecho de que sea el detective el encargado de realizarlas pueda constituir una exoneración de tal obligación ${ }^{25}$.

Como se ha señalado, cuestión distinta sería cuando la videovigilancia se realiza fuera del centro de trabajo o al margen de las relaciones de trabajo, en tanto que no se establece ninguna obligación expresa de informar al interesado previamente. En estos casos, existen dos momentos fundamentales al respecto de la cesión de datos del investigado que deben ser destacados y comentados. El primer momento consiste en la entrega de datos por parte del cliente al detective. Al producirse la contratación del servicio, el cliente no se limita a concertar el

23 Carlos González González, "Control empresarial de la actividad laboral mediante la videovigilancia y colisión con los derechos fundamentales del trabajador. Novedades de la Ley Orgánica 3/2018, de 5 de diciembre, de Protección de Datos Personales y garantía de los derechos digitales”, Revista Aranzadi Doctrinal, núm. 4 (2019). Versión digital.

24 Cruz Villalón, "Las facultades de control del empleador ...".

25 González González, "Control empresarial de la actividad laboral ...”. 
trabajo, sino que también debe proporcionar datos personales de la persona que va a ser investigada, de forma que pueda tener lugar la investigación ${ }^{26}$. El segundo momento se constituye por la entrega del informe del detective al cliente. En este caso, se trata de datos que no han sido cedidos por parte del investigado y que, por tanto, este puede no saber ni tan siquiera que se encuentran en circulación. Se hace referencia a fotografías, grabaciones, así como a mera información sobre sus hábitos, comportamientos, aparentes limitaciones físicas, etc.

Es tras la finalización del trabajo y entrega del informe (esto es, cuando los datos fuesen cedidos por el detective al cliente por primera vez) cuando la regulación contenida en el RGPD implicaría la obligación de informar al interesado de tales circunstancias ${ }^{27}$. Sin embargo, esta obligación se evitaría en tanto que el detective no actúa como encargado de tratamiento (art. 4.8 RGPD), ni como responsable del mismo (art. 4.7 RGPD), lo que salvaría la prohibición de comunicar al investigado de las cesiones de datos realizados entre ellos ${ }^{28}$. Sin embargo, como se ha señalado, lo anterior no obsta a que deba cumplirse con la obligación de información respecto de la existencia de nuevos datos personales que se han tomado sin su consentimiento, y ello en el plazo máximo de un mes (art. 14.3 RGPD).

Finalmente, debe señalarse que, una vez concluido el informe de investigación, este deberá conservarse archivado, al menos, durante tres años. Transcurrido este plazo, las imágenes y sonidos grabados durante las investigaciones deberán destruirse, salvo que se encuentren relacionadas con un procedimiento judicial, una investigación policial o un procedimiento sancionador (art. 49.4 LSP). En todo caso, el tratamiento de dichas imágenes y sonidos deberá observar lo establecido en la normativa sobre protección de datos de carácter personal, especialmente sobre el bloqueo de datos previsto en la misma.

26 Estos pueden ser de muy distintos tipos: identidad (nombre y apellidos), domicilio (al que el detective deberá dirigirse, por ejemplo, en el supuesto de investigaciones relacionadas con la capacidad laboral), fotografías (de forma que pueda identificarse visualmente al investigado), patologías sufridas por el trabajador (de modo que el detective pueda centrar su investigación en las actividades para las que supuestamente el investigado se encuentra limitado), etc.

27 González González, "Control empresarial de la actividad laboral ....".

28 Mercader Uguina, "La protección de datos del informe ..." (Bibl. cit). 


\section{EL INFORME DE DETECTIVES COMO MEDIO DE PRUEBA}

Como se ha expuesto, el resultado de la investigación podrá hacerse valer en el procedimiento judicial correspondiente. En el presente apartado se analiza la forma en que dicho informe puede incorporarse al procedimiento judicial y la fiscalización judicial a la que debe quedar sometido, así como las consecuencias que habrá que aplicar en los supuestos en que se aprecie que la prueba vulnera derechos fundamentales.

\subsection{LA PRUEBA DE DETECTIVES EN LA JURISDICCIÓN SOCIAL}

La prueba de detectives no se encuentra explícitamente regulada en nuestras leyes procesales. Esto es así porque no se considera como un medio de prueba autónomo, pudiendo adoptar la actuación del detective distintas formas. En concreto, en el ámbito de la jurisdicción social, en forma de prueba testifical o como aportación de medios de reproducción de la palabra, de la imagen y del sonido, etc. Esto es así porque la prueba de detectives difícilmente se limita a la actuación del investigador privado, sino que habitualmente se complementa, entre otros, con medios electrónicos de videovigilancia.

Debe comenzar aclarándose que es jurisprudencia consolidada que el informe de detective no tiene el carácter de prueba documental ${ }^{29}$, sino de lo que se ha venido a denominar "testifical documentada" 30 o "testifical impropia" 31. Esta circunstancia resulta especialmente relevante, en tanto que, por ejemplo, no se permitirá que sobre dicha prueba se sustente una revisión fáctica por vía de recurso, al exigirse que esta se sustente en prueba documental (art. 193.b LRJS, para el caso del recurso de suplicación, y art. 207.d LRJS, para el recurso de casación ordinaria). Por el mismo motivo, tampoco podrá sustentar una solicitud de revisión de sentencia firme (art. 236.1 LRJS en relación con el art. 510.1.1 ${ }^{\circ}$ LEC). A igual conclusión conduce la valoración de las imágenes o

29 STS de 6 de noviembre de 1990 (ECLI:ES:TS:1990:17467).

30 STS de 25 de marzo de 2002 (ECLI:ES:TS:2002:9425).

31 STS de 24 de febrero de 1992 (ECLI:ES:TS:1992:1469). 
sonidos que se puedan incorporar a dicho informe, cuya eficacia revisoria también ha sido descartada ${ }^{32}$. Otro de los efectos destacados de su ausencia de consideración como prueba documental es que la apreciación de una falsedad no acarreará la suspensión del acto de juicio para interponer la correspondiente querella (art. 86.2 LRJS), sin perjuicio de la posibilidad de ejercitar las correspondientes acciones penales con posterioridad.

En su lugar, al tratarse de una prueba testifical o de reproducción de la imagen y sonido, se somete a los criterios generales para este tipo de prueba, debiendo valorarse según las genéricamente llamadas reglas de la sana crítica (art. 376 LEC en el caso de la prueba testifical y art. 384.3 LEC en el caso de las grabaciones y fotografías). Pese a lo expuesto, la Jurisprudencia les otorga, al menos a priori, una credibilidad cualificada 33 .

\subsection{EL CONTROL JUDICIAL DE LA VALIDEZ DE LA PRUEBA}

El análisis de la licitud de la prueba de detectives deberá ajustarse a los límites generales de validez de la prueba. El art. 90.2 LRJS establece que "no se admitirán pruebas que tuvieran su origen o que se hubieran obtenido, directa o indirectamente, mediante procedimientos que supongan violación de derechos fundamentales o libertades públicas”. Esta norma supone la adaptación a la jurisdicción social del primer apartado del artículo 11 LOPJ, que establece que "no surtirán efecto las pruebas obtenidas, directa o indirectamente, violentando los derechos o libertades fundamentales". De este modo, el respeto a los derechos fundamentales se sitúa como condición fundamental para que la prueba pueda surtir efectos, debiendo ser desterrada del procedimiento toda aquella que atente contra tales derechos. En la práctica, esta colisión se produce

32 STS de 26 de noviembre de 2012 (ECLI:ES:TS:2012:8471).

33 La STS de 6 de noviembre de 1990 (ECLI:ES:TS:1990:17467) señala al respecto que "el testimonio emitido por los detectives privados tiene, en favor de su veracidad, no sólo la garantía de profesionalidad exigible y, en principio, presumible en una profesión, reglamentada legalmente, sino también la que, de modo innegable, proporciona la precisa y continuada dedicación al objeto del ulterior testimonio a emitir y las complementarias acreditaciones, gráficas o sonoras, de que, este último, suele ir acompañado. Ello no obsta, obviamente, a la neutralización de dicho medio probatorio por otro u otros, de superior o idéntico valor justificativo, obrante en los autos". 
fundamentalmente con los derechos recogidos en el art. 18 de la Constitución (intimidad, inviolabilidad del domicilio...), aunque no en exclusiva, afectando también a otros (derecho de huelga, libertad sindical, libertad ideológica...).

De este modo, deberán valorarse los términos en que se efectuó el encargo al detective, correspondiéndole a quien propone la práctica de dicha prueba acreditar que tanto la captación como el uso de los datos resulta necesario, "no en términos de oportunidad sino de esencialidad, esto es, que la ejecución del contrato o el debido cumplimiento de los deberes contractuales requiera indefectiblemente el tratamiento de los datos personales" 34 . Dicha ponderación remite nuevamente al triple test de proporcionalidad -al que se alude a continuación-, a cuyo efecto resultará determinante fiscalizar los términos en que se produjo el encargo, siendo ello fundamental para acreditar la idoneidad de la prueba.

Asimismo, resulta necesario analizar si la actuación del detective resulta respetuosa con tales derechos fundamentales, a cuyo efecto habrá que realizar un análisis casuístico en atención al tipo de investigación realizada, medios empleados para la misma y forma en que se ha llevado a cabo. Además, el juzgador deberá revisar si la actuación del detective ha respetado el triple juicio de proporcionalidad. Es decir, deberá valorar si la prueba era adecuada para conseguir el objetivo perseguido (idónea); si era la menos lesiva para los derechos fundamentales de entre las demás que también podrían haberse escogido (necesaria); y si, pese a lo anterior, de la utilización de la prueba se derivan más beneficios que perjuicios sobre los intereses en conflicto (proporcionalidad en sentido estricto).

A tal objeto, la doctrina del TEDH ha establecido que debe atenderse a determinados factores, que serán los que permitirán apreciar la licitud de la prueba: grado de intromisión por parte de quien encarga la investigación, concurrencia de una legítima razón para dicha investigación, inexistencia de medios menos invasivos para la obtención de la información, el destino que se da a la información obtenida y las medidas adoptadas para garantizar los derechos del

34 Garrido Pérez, "La actuación de los detectives privados ...”, 246. 
investigado. También adquiere una especial relevancia la delimitación previa del ámbito de actuación35.

Todo lo expuesto implica que el juez deberá examinar si la intervención del detective ha sido respetuosa con los derechos fundamentales, debiendo realizar este análisis incluso de oficio36. Este análisis implicará, necesariamente, que se examinen los términos en que se produjo el encargo, la justificación del mismo y las causas que acreditaron su necesidad.

Como colofón de lo expuesto, la intervención del detective debe ser respetuosa con las obligaciones en materia de protección de datos, so pena de quedar la prueba excluida del procedimiento. Ello implicará que deba acreditarse en el acto de juicio por parte de quien propone la prueba que se ha cumplido con todas las exigencias legales anteriormente expuestas. En concreto, resultará fundamental que se acredite que la cesión de datos del cliente al detective, necesaria para comenzar la investigación, fue lícita. Además, deberá igualmente acreditarse que, tras la emisión del informe, y en el momento en que se entregó al cliente, se dio igualmente traslado al investigado, con todos los requisitos anteriormente aludidos. Lo contrario supondrá que la cesión de datos no respetó los derechos del investigado, lo que no permitió a este, entre otras cuestiones, ejercitar sus derechos.

\subsection{IMPLICACIONES DE LA PRUEBA OBTENIDA CON VULNERACIÓN DE DERECHOS}

Como se ha visto, tanto la normativa reguladora del trabajo de los detectives, como la de protección de datos, establecen determinadas obligaciones que deben ser atendidas antes, durante y después de los encargos. A continuación, se

35 Esta cuestión es abordada con más extensión por María Elisa Cuadros Garrido, "La protección de los derechos fundamentales de la persona trabajadora ante la utilización de GPS: ¿̇reformulación o continuidad?", Lan harremanak: Revista de relaciones laborales, núm. 42, Ejemplar dedicado a: Digitalización, conciliación y trabajo como mercancía = Digitalizazioa, uztartzea eta lana merkatalgai gisa (2019): 131.

36 Así se desprende de los taxativos términos en que se encuentra redactado el art. 90.2 LRJS, al establecer que "no se admitirán" tales pruebas, añadiendo a continuación que esta cuestión podrá suscitarse por cualquiera de las partes o, incluso, de oficio. 
analizan las consecuencias para los supuestos en que no se respeten tales exigencias.

La primera y fundamental consecuencia de un incumplimiento en la materia que implique la vulneración de los derechos fundamentales debe determinar la declaración de la nulidad de la prueba y su expulsión del procedimiento, y con ella de las evidencias que se hayan obtenido a raíz de la misma, por aplicación de la doctrina anglosajona del fruto del árbol envenenado ${ }^{37}$. Evidentemente, esta consideración se aplicará sin ambages a los supuestos en que sea vulnerado el derecho a la protección de datos 38 .

Sin embargo, con independencia de lo anterior, existen otras opciones que pueden llevarse a cabo cuando se ha producido una vulneración de derechos fundamentales.

Como se ha señalado, la vulneración de derechos fundamentales no se corrige con la mera anulación del acto, sino que existen muchos otros aspectos que deben ser tutelados al objeto de conseguir la total reparación del lesionado39. De este modo, cuando la prueba del detective se obtiene vulnerando derechos fundamentales, esta puede determinar la nulidad de la actuación. Sin embargo, no en todo caso quedará resarcida de esta manera la vulneración, así que existe la posibilidad de ejercitar en un procedimiento posterior una acción judicial al objeto de obtener dicha reparación.

En estos casos, la demanda podrá dirigirse también contra el tercero que resulte responsable de la vulneración, "con independencia del tipo de vínculo

37 Señala la STSJ Canarias/Tenerife de 24 de enero de 2020 (ECLI:ES:TSJICAN:2020:81) que, si la prueba "ha sido obtenida mediante una actuación vulneradora de los derechos fundamentales, procede la anulación de su efectividad probatoria, y, como consecuencia del denominado «efecto dominó», que derriba y arrastra toda la prueba derivada de la vulneración constitucional, ello determina el decaimiento de todas las pruebas posteriores derivadas de ella”. En este mismo sentido se pronuncia la reciente STS de 19 de febrero de 2020 (ECLI.ES.TS.2020.848).

38 González González, "Control empresarial de la actividad laboral ...".

39 José Fernando Lousada Arochena, "Las cláusulas de protección jurisdiccional efectiva de la igualdad de los sexos en la Ley Reguladora de la Jurisdicción Social”. Lan harremanak: Revista de relaciones laborales, núm. 25, Ejemplar dedicado a: Igualdad y no discriminación por razón de género en las relaciones laborales = Berdintasuna eta diskriminaziorik eza lan harremanetan, generoa dela medio (2011): 231-265. 
que le una al empresario" (177.4 LRJS). De este modo, se podrá dirigir la demanda frente al empleador y también frente al detective. En estos casos, el detective podrá ser declarado responsable de la vulneración, debiendo responder de las consecuencias de la vulneración e, incluso, de la resarcitoria, pudiendo ser condenado a afrontar el pago de una indemnización.

Podría plantearse, igualmente, el supuesto de que el empresario encargue al detective que realice una investigación sobre determinado aspecto, y que dicho detective sea el que se extralimite en sus funciones y acuda a medios prohibidos para realizar su trabajo. Como se ha señalado, "el interés legítimo del empleador en obtener datos personales de su trabajador para fines contractuales, ni puede justificar ni eximir una supuesta conducta indebida del detective privado de naturaleza lesiva a los derechos de personalidad del trabajador"40. De este modo, aunque el empleador pueda no tener responsabilidad en ello, la aportación de dicho informe al acto de juicio implica que se valga de medios ilícitos y, por tanto, no podrá quedar eximido de la responsabilidad de un tercero.

\section{CONCLUSIONES}

Algunos autores ya han destacado la dificultad de controlar el uso que se haga de la información obtenida o que, incluso, el detective limite su trabajo al encargo que se realiza y aporte información exclusivamente referida a esa cuestión, habiendo destacado que ello no debe traducirse en la prohibición de la investigación de la vida privada. De hecho, tales actuaciones se pueden justificar en que es precisamente un profesional el encargado de realizarlas. Incluso, se ha apuntado que es al propio detective a quien le interesa la discreción en todas las direcciones, señalando que el cliente dejará de fiarse de él si ve que incumple tales criterios ${ }^{41}$.

40 Garrido Pérez, "La actuación de los detectives privados ...”, 238.

41 Díaz Rodríguez: Detectives y vigilantes privados... (Bibl. Cit.), capítulo III ("Poder empresarial de control mediante vigilantes y detectives"), apartado 2.10 ("Legalidad de la flagrancia buscada”). 
Muy lejos de esa apreciación, la experiencia nos demuestra que en la práctica no ocurre así. Desgraciadamente, en los últimos años ha saltado a la luz una serie de escándalos relacionados con distintas investigaciones que han ido descubriendo cómo algunos individuos realizaban averiguaciones para venderlas al mejor postor ${ }^{42}$. En consecuencia, consideramos que la realidad evidencia que precisamente la falta de ética profesional y la ausencia de respeto a la legalidad puede resultar un añadido a la hora de ser contratado para determinados propósitos.

Por lo tanto, las herramientas para evitar estas actuaciones no deben limitarse al establecimiento de un rígido control judicial de la validez de tales actuaciones. Muy al contrario, y sin menospreciar la relevancia de la intervención judicial, es preciso que se regule de forma mucho más minuciosa la actividad de investigación privada43. Y ello precisamente desde el momento en que las averiguaciones no saldrán en muchos casos a la luz pública, lo que no impide que se haya producido una grave vulneración del derecho a la vida privada e, incluso, a la intimidad.

Este particular problema podría quedar salvado por la vía de establecer nuevos criterios a la hora de formalizar los expedientes de contratación. En concreto, bastaría con ampliar las exigencias del art. 9.2 LSP, de forma que no baste con comunicar la celebración del contrato a la administración competente, sino debiendo incorporar también las pruebas que justifican la misma y su contenido motivado. Solo de este modo quedaría constancia efectiva del cumplimiento de los tres requisitos: se podría acreditar que la fecha de la firma del mismo es la

42 Es paradigmático de lo anterior el llamado Caso Villarejo, en referencia a un excomisario del Cuerpo Nacional de Policía al que se imputa, entre otros, la realización de trabajos de este tipo. Este asunto ha salido a la luz como consecuencia de afectar a numerosos personajes públicos y líderes políticos, siendo la información obtenida filtrada a sucesivos medios de comunicación, hasta que alguno de ellos terminó por darle publicidad. Igualmente, se ha podido saber que estos mismos servicios eran empleados por grandes corporaciones para investigar a entidades rivales o, incluso, a sus propios directivos.

43 Teniendo en cuenta, además, que precisamente el carácter parco de la normativa que regula a los detectives ha implicado que los pronunciamientos judiciales hayan tenido difícil establecer criterios realmente generales, cayendo con frecuencia en el casuismo. En este sentido, véase Díaz Rodríguez: Detectives y vigilantes privados... (Bibl. Cit.), capítulo III ("Poder empresarial de control mediante vigilantes y detectives"). 
real y que no se ha cumplimentado (o subsanado) posteriormente; podría demostrarse que el encargo estaba justificado previamente a su inicio; y podría fiscalizarse la existencia de pruebas que apoyasen la necesidad del encargo. Solo de este modo podrá garantizarse el respeto de los derechos de la persona investigada, así como su efectiva supervisión judicial, por la vía de requerir dicho expediente en el momento del análisis de la prueba.

Además, el RGPD y la LOPDyGDD han incluido varias obligaciones que deben ser necesariamente atendidas por los detectives, en cuanto a la forma de realizar sus actuaciones. Estas exigencias atañen especialmente a los supuestos en que un empresario decida emplear mecanismos de captación de la imagen o el sonido dentro del centro de trabajo. En nuestra opinión, no podría aceptarse que el empleador pueda sortear tales obligaciones por la vía de acudir a la contratación de un detective y asignarle el encargo de realizar dichas actuaciones, sino que este deberá respetar escrupulosamente y cargar con las exigencias establecidas para quien le realiza el encargo.

En conclusión, debe señalarse que las investigaciones privadas deben ser respetuosas con los derechos fundamentales de los afectados. El trabajo de los detectives permite acceder a datos personales muy relevantes, lo que resulta de gran interés y utilidad para aquellos que realizan el encargo, ante las posibilidades que ello les concede (despedir a un trabajador problemático o poner fin a la prestación de un beneficiario que no la necesita). La otra cara de la moneda es la necesidad de evitar abusos y extralimitaciones en el empleo de dicha información, motivo por el que resulta fundamental establecer límites, ya que, como señala CUADROS GARRIDO, "si la información es poder, su tratamiento y control no es en grado sumo" 44 .

44 Cuadros Garrido, “La protección de los derechos fundamentales de la persona trabajadora ...”, 129. 


\section{REFERENCIAS BIBLIOGRÁFICAS}

Areta Martínez, María. "Solicitud de un certificado de antecedentes penales a los trabajadores de nuevo ingreso y tratamiento de datos de carácter personal. SAN-SOC núm. 14/2020, de 10 de febrero". Revista de Jurisprudencia Laboral 3 (2020): 1-12.

Cuadros Garrido, María Elisa. "La protección de los derechos fundamentales de la persona trabajadora ante la utilización de GPS: ¿̇reformulación o continuidad?”, Lan harremanak: Revista de relaciones laborales, núm. 42, Ejemplar dedicado a: Digitalización, conciliación y trabajo como mercancía = Digitalizazioa, uztartzea eta lana merkatalgaigisa (2019): 127-148.

Cruz Villalón, Jesús. "Las facultades de control del empleador ante los cambios organizativos y tecnológicos”, Temas laborales: Revista andaluza de trabajo y bienestar social 150 (2019): 13-44.

Mercader Uguina, Jesús Ramón. "La protección de datos del informe de detectives privados”. En La actividad de los detectives privados en el ámbito laboral. Aspectos sustantivos y procesales de la obtención de la prueba. Dirigido por Eduardo Enrique Taléns Visconti y Ma Ángeles Valls Genovard. Madrid: Wolters Kluwer, 2020.

Díaz Rodríguez, Juan Miguel. Detectives y vigilantes privados en el ámbito laboral: poder empresarial y prueba judicial. Valencia: Tirant lo Blanch, 2013 [Versión electrónica. Base de datos Tirant online]. Acceso el 3 de enero de 2021.

García Ninet, José Ignacio y Fernando de Vicente Pachés. "El derecho valor a la dignidad humana y el derecho a la protección de datos personales en la Constitución Europea”. Revista del Ministerio de Trabajo y Asuntos Sociales 57 (2005): 137-192.

Garrido Pérez, Eva. "La actuación de los detectives privados como instrumento del control empresarial”. Temas laborales: Revista andaluza de trabajo y bienestar social 150 (2019): 227-247.

González González, Carlos. "Control empresarial de la actividad laboral mediante la videovigilancia y colisión con los derechos fundamentales del trabajador. Novedades de la Ley Orgánica 3/2018, de 5 de diciembre, de Protección de Datos Personales y garantía de los derechos digitales”. Revista Aranzadi Doctrinal 4 (2019). Versión digital.

Lousada Arochena, José Fernando. "Las cláusulas de protección jurisdiccional efectiva de la igualdad de los sexos en la Ley Reguladora de la Jurisdicción Social”. Lan harremanak: Revista de relaciones laborales 25. Ejemplar dedicado a: Igualdad y no discriminación por razón de género en las relaciones laborales = Berdintasuna eta diskriminaziorik eza lan harremanetan, generoa dela medio (2011): 231-265. 
Palomeque López, Manuel Carlos. Los derechos laborales en la Constitución Española. Madrid: Centro de Estudios Constitucionales, 1991.

Polo Roca, Andoni. "El derecho a la protección de datos personales y su reflejo en el consentimiento del interesado". Revista de Derecho Político 108 (2020): 165-193.

Sempere Navarro, Antonio Vicente y Carolina San Martín Mazzuconi. Nuevas tecnologías y relaciones laborales. Valencia: Tirant lo Blanch, 2002.

Serrano Pérez, María Mercedes y Lucrecio Rebollo Delgado. El derecho fundamental a la intimidad. $2^{\mathrm{a}}$ edición. Madrid: Editorial Dykinson, 2005.

\author{
Antonio Folgoso Olmo \\ Abogado Laboralista \\ Colegio de Abogados de Granada \\ antonio@folgosoabogados.com \\ https://orcid.org/oooo-0002-3555-4500
}

